\title{
Variante de la anatomía de los músculos papilares como causa de insuficiencia mitral. Un caso de
} válvula mitral asimétrica en paracaídas-like

\author{
Anatomy variant of the papillary muscles as a cause of mitral regurgitation. Case report of a parachute-like \\ asymmetric mitral valve \\ Variante da anatomia dos músculos papilares como causa da regurgitação mitral. Relato de caso de uma \\ válvula mitral assimétrica semelhante a um pára-quedas.
}

\section{Jorge Miguel Briceño Revillo ${ }^{1}$, Juan Ramon y Cajal Calvo ${ }^{2,3}$, Jorge Melero Polo ${ }^{1}$, Juan Francisco Cueva Recalde ${ }^{1}$, David Ibañez Muñoz ${ }^{2}$}

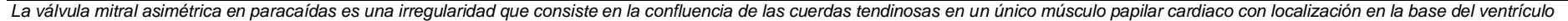
izquierdo. La clínica varía desde cuadros asintomáticos hasta casos con importante insuficiencia valvular con repercusión hemodinámica. Para su diagnóstico es importante una correcta historia

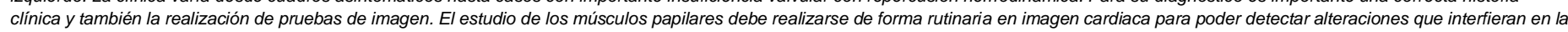
correcta dinámica valvular.
\end{abstract}

\section{Conceptos clave:}

- Que conocemos del tema:

La válvula mitral en paracaídas-like es una anomalía congénita poco común que causa cuadros clínicos diversos a nivel hemodinámico caracterizados por la presencia de dos músculos papilares siendo uno de ellos más elongado y adherido al velo mitral de forma contigua. Las herramientas diagnósticas que han demostrado ser útiles para el diagnóstico de esta enfermedad incluyen la ecocardiografía transtorácica, transesofágica y la resonancia magnética cardiaca.

- Que aporta este trabajo:

Se presenta el caso de una paciente con el hallazgo incidental mediante técnicas de imagen de una válvula mitral en paracaídaslike. Las imágenes tanto ecográficas como de la resonancia magnética muestran el patrón característico de esta patología, Este artículo aporta conocimientos centrados en las características anatómicas de dicha anomalía estructural correlacionándolo directamente con los hallazgos radiológicos.

1. Servicio Cardiología. Hospital Clínico Universitario Lozano Blesa. Zaragoza. España.

2. Servicio de Radiodiagnóstico. Hospital Clínico Universitario 2. Servino Blesa. Zaragoza. España.

3. Mail de contacto: jramonycajalc@gmail.com

Recibido: 2021-08-28 Aceptado: 2021-10-17

DOI: http://dx.doi.org/10.31053/1853.0605.v78.n4.33876

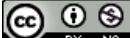

(c) Universidad Nacional de Córdoba

\section{Resumen:}

Introducción: La válvula mitral en paracaídas-like es una anomalía congénita caracterizada por una disposición asimétrica de los músculos papilares, siendo las pruebas de imagen cardiaca el procedimiento de elección tanto para el diagnóstico anatómico como para realizar la valoración funcional de este tipo de anomalía estructural.

Caso Clínico: Paciente con cuadro de descompensación hemodinámica en el cual se diagnóstica de manera incidental de una valvulopatía mitral en forma de paracaídas-like. Los hallazgos de imagen por ecocardiografía transtorácica y resonancia magnética ponen de manifiesto la presencia de 2 músculos papilares, ambos con inserción en segmento lateral apical confirmando una válvula mitral asimétrica con similitud a su morfología en paracaídas.

Discusión: La válvula mitral en paracaídas es una anomalía congénita poco común constituyente en la presencia de dos músculos papilares siendo uno de ellos más elongado y adherido al velo mitral de forma contigua, mostrándose en algunos casos pequeñas cuerdas tendinosas asociadas. Puede presentar una evolución benigna siendo un hallazgo casual o asociarse a repercusión hemodinámica valvular como el caso presentado.

Conclusión: La válvula mitral en paracaídas-like es una anomalía congénita caracterizada por una disposición asimétrica de los músculos papilares, siendo su evolución muy variable, pudiendo pasar desapercibida o afectando de forma significativa a la mecánica valvular.

Palabras claves: válvula mitral; músculos papilares; anomalías congénitas.

\section{Abstract}

Introduction: The parachute-like mitral valve is a congenital anomaly characterized by an asymmetric arrangement of the papillary muscles, with cardiac imaging being the procedure of choice both for anatomical diagnosis and for functional assessment of this type of structural anomaly.

Clinical Case: Patient with hemodynamic decompensation in which a parachute-like mitral valve disease was diagnosed incidentally. Image findings by transthoracic echocardiography and magnetic resonance revealed the presence of 2 papillary muscles, both with apical lateral segment insertion, confirming an asymmetric mitral valve similar to its parachute morphology.

Discussion: The parachute mitral valve is an uncommon congenital anomaly constituting the presence of two papillary muscles, one of them being more elongated and adhering to the mitral leaflet in a contiguous way, showing in some cases small associated tendinous chords. It can present a benign evolution being a chance finding or associated with valvular hemodynamic repercussion as the case presented.

Conclusion: The parachute-like mitral valve is a congenital anomaly characterized by an asymmetric arrangement of the papillary muscles, its evolution being highly variable, being able to go unnoticed or significantly affecting valve mechanics.

Keywords: mitral valve; papillary muscles; congenital abnormalities.

\section{Resumo}

Introdução: A válvula mitral em forma de paraquedas é uma anomalia congênita caracterizada por um arranjo assimétrico dos músculos papilares, sendo a imagem cardíaca o procedimento de escolha tanto para diagnóstico anatômico quanto para avaliação funcional desse tipo de anomalia estrutural.

Caso Clínico: Paciente com descompensação hemodinâmica com diagnóstico incidental de valvopatia mitral tipo pára-quedas. Os achados de imagem pela ecocardiografia transtorácica e ressonância magnética revelaram a presença de 2 músculos papilares, ambos com inserção do segmento lateral apical, confirmando uma válvula mitral assimétrica semelhante à sua morfologia de paraquedas.

Discussão: A válvula mitral em pára-quedas é uma anomalia congênita incomum, constituindo-se na presença de dois músculos papilares, sendo um deles mais alongado e aderindo ao folheto mitral de forma contígua, apresentando em alguns casos pequenas cordas tendíneas associadas. Pode apresentar evolução benigna sendo achado casual ou associado a repercussão hemodinâmica valvar conforme o caso apresentado.

Conclusão: A válvula mitral em forma de paraquedas é uma anomalia congênita caracterizada por um arranjo assimétrico dos músculos papilares, sendo sua evolução muito variável, podendo passar despercebida ou afetar significativamente a mecânica valvar.

Palavras chave: valva mitral; músculos papilares; anormalidades congénitas. 


\section{INTRODUCCION}

La válvula mitral en paracaídas-like consiste en la convergencia de las cuerdas tendinosas en un único músculo papilar con localización en la base del ventrículo izquierdo. Si bien en la mayoría de las ocasiones este músculo resulta de la fusión de ambos músculos papilares, en ciertas ocasiones existe un segundo músculo papilar accesorio sobre el que no se insertan cuerdas tendinosas. Las pruebas de imagen con la ecocardiografía transtorácica y la resonancia magnética son el procedimiento de elección tanto para el diagnóstico anatómico como para realizar la valoración funcional de este tipo de anomalía estructural.

\section{CASO CLÍNICO}

Se presenta el caso de una mujer de 42 de años con antecedentes de infecciones bronquiales de repetición y dislipemia en la que durante un ingreso a causa de una infección respiratoria y descompensación hemodinámica se detecta una valvulopatía mitral debida a una variante anatómica valvular poco frecuente en la población general.

La paciente ingresa en el servicio de infecciosas de nuestro centro por cuadro de tos seca, febrícula y disnea de moderados esfuerzos (NYHA II) de días de evolución que tras el tratamiento inicial desde Atención Primaria no evoluciona favorablemente por lo que acude finalmente a urgencias hospitalarias.

En la exploración física destaca ligera taquipnea y disnea conversacional, tonos cardiacos con soplo sistólico en foco mitral III/VI irradiado a axila y crepitantes bibasales pulmonares.

En las pruebas complementarias se descarta infección por SARS-CoV2 con prueba de antígeno, serología y PCR negativos. En la radiografía de tórax se pone de manifiesto un patrón intersticial con aumento de densidad en la base pulmonar derecha y derrame pleural bilateral de escasa cuantía. Se completa el estudio con TC torácica que muestra aumento de densidad generalizada que sugiere edema intersticial compatible con cuadro de descompensación hemodinámica, cardiomegalia con dilatación de cavidades izquierdas y derrame pleural bilateral. Ante estos hallazgos se sospecha cuadro de insuficiencia cardiaca congestiva con infección respiratoria como desencadenante por lo que se solicita un ecocardiograma transtorácico para completar el estudio. El ecocardiograma (figura 1), objetiva una válvula mitral de velos ligeramente engrosados, siendo el velo posterior corto con una marcada reducción de su movilidad, y el velo anterior con ligera restricción, especialmente en su borde libre. El estudio impresiona de ligera restricción a la apertura si bien presenta un área valvular por planimetría de $2,5 \mathrm{~cm}^{2}$ dentro de la normalidad. Se visualizan varios jets de regurgitación comisurales que prácticamente alcanzan el techo de aurícula izquierda (AI), aunque sin invertir el flujo en venas pulmonares. Únicamente se logra visualizar un músculo papilar de localización posterolateral, sospechando la presencia de una válvula mitral en paracaídas. El ventrículo izquierdo no presenta dilatación con función ventricular conservada sin asimetrías de la contractilidad.

Tras el tratamiento broncodilatador y diurético la paciente muestra mejoría significativa por lo que se decide alta domiciliaria y completar estudio mediante ecocardiograma transesofágico de la valvulopatía mitral de forma ambulatoria. Durante la realización del mismo la paciente desarrolla intolerancia a la sonda transesofágica no pudiéndose completar el estudio e indicándose la realización de resonancia magnética cardiaca cuyos hallazgos expresan dilatación de la aurícula izquierda, un ventrículo izquierdo sin dilatación ni hipertrofia y una fracción de eyección (FEVI) conservada sin alteraciones segmentarias en su contractilidad. Se observan 2 músculos papilares, ambos con inserción en segmento lateral apical, siendo el músculo papilar anterior de mayor longitud e insertándose directamente en el velo anterior mitral. El músculo papilar posterior se inserta en el velo posterior mitral también de forma directa, confirmando una válvula mitral asimétrica con similitud a su morfología en paracaídas (figuras 2A y 2B).

Se decide finalmente control por Cardiólogo de área presentando buena evolución con tratamiento diurético a dosis bajas.

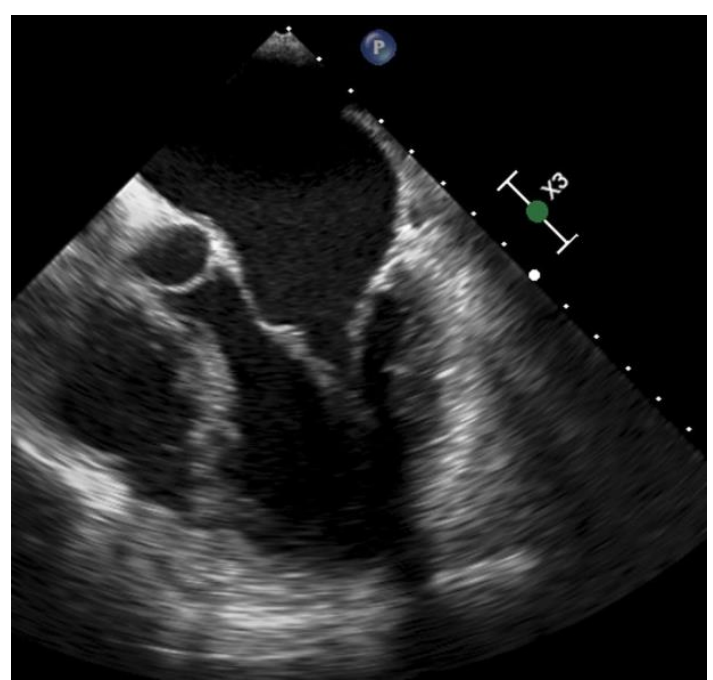

Figura 1: Ecocardiografía transtorácica, plano medioesofágico 4 cámaras modificado. Se visualiza el origen de ambos músculos papilares en la pared lateral ventricular izquierda y la inserción directa al velo anterior mitral.

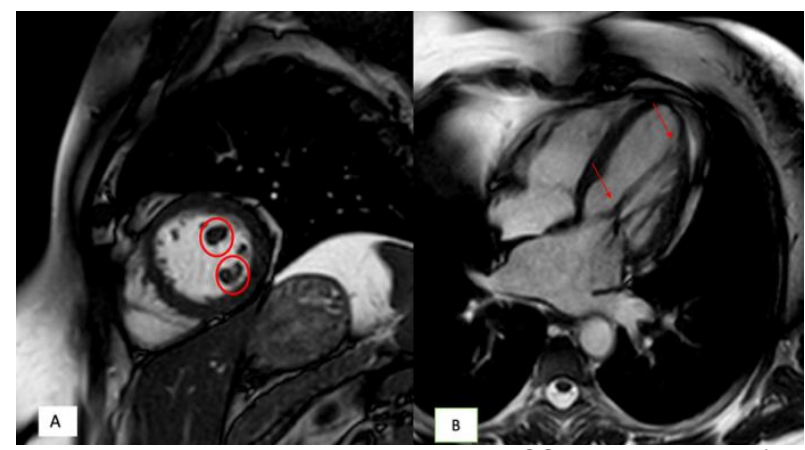

Figuras 2A y 2B: RM cardiaca secuencias SSFP en eje corto (Figura $2 \mathrm{~A})$ y cuatro cámaras (2B). Se visualiza en la figura 2A la presencia de dos músculos papilares (círculos rojos) con inserción en valva mitral y anclaje de cuerda tendinosa a nivel apical del ventrículo izquierdo (flechas).

\section{DISCUSIÓN}

La insuficiencia mitral es una de las valvulopatías más frecuentes junto con la estenosis aórtica. Su etiología más frecuente es la degenerativa debido a depósitos de calcio, pudiéndose producir a distintos niveles del aparato valvular. Otras causas conocidas son la degeneración mixoide asociada o no a prolapso mitral, la endocarditis infecciosa, la afectación valvular reumática y la denominada insuficiencia mitral funcional que se debe a dilatación de cavidades como el ventrículo o aurícula izquierda.

A pesar de ser infrecuente como etiología aislada, la anatomía de los músculos papilares también juega un papel importante en la etiopatogenia de esta valvulopatía ${ }^{1}$. Es bien conocida la insuficiencia mitral de origen isquémico por acinesia de los músculos papilares provocando una restricción de movimiento del velo mitral asociado. No obstante, variantes de la anatomía de los músculos papilares así como la hipertrofia o adelgazamiento y su localización y extensión están intrínsecamente relacionadas con la patología valvular mitral. En múltiples estudios de imagen para la valoración de insuficiencia mitral no se realiza un análisis sistemático de la anatomía de los músculos papilares, resultando una valoración inadecuada y una comprensión limitada de la causa de la misma, pudiendo influir finalmente en la actitud terapéutica y el pronóstico del paciente.

Habitualmente existen dos músculos papilares en el ventrículo izquierdo: el anterolateral y el posteromedial. El músculo papilar anterolateral se origina entre la pared anterolateral e inferolateral y el posteromedial cerca de la unión de la pared inferior y el septo. La unión 
de estos músculos a la pared del ventrículo izquierdo también es variable, pudiendo aparecer como una estructura unitaria a modo de "dedo" o con una base de implantación ancha y múltiples puentes trabeculares. Sin embargo, se han observado ${ }^{2}$ que la mayoría de los músculos papilares no están unidos de forma directa con la pared del ventrículo izquierdo sino a una red de trabéculas y entramado muscular que surge de la pared del ventrículo izquierdo. Los músculos papilares están compuestos por un cuerpo principal del que se originan seis "cabezas" de las cuales parten las cuerdas tendinosas (primarias, secundarias y terciarias) que se implantan en ambos velos mitrales.

En nuestro caso nos encontramos ante una anomalía congénita de los músculos papilares denominada válvula mitral en paracaídas-like. Se denomina así debido a su similitud en cuanto la disposición asimétrica de los músculos papilares, pero a diferencia de la válvula mitral en paracaídas, presenta dos músculos papilares en lugar de uno ${ }^{3}$. Los dos músculos papilares se originan en el segmento lateral apical, siendo el anterior de mayor longitud, insertándose directamente en el velo anterior mitral. El posterior también se introduce de forma directa al velo posterior mitral pero su longitud es menor, provocando un cierre excéntrico y defectuoso de la válvula mitral en sístole y originando una insuficiencia mitral moderada.

La característica típica de la válvula mitral en paracaídas-like es por tanto la presencia de dos músculos papilares siendo uno de ellos más elongado y adherido al velo mitral de forma contigua, mostrándose en algunos casos pequeñas cuerdas tendinosas asociadas. Esta entidad se considera más frecuente que la válvula mitral en paracaídas, típicamente asociada al complejo de Shone, pudiendo presentarse de forma aislada ${ }^{4}$. Puede presentar una evolución benigna siendo un hallazgo casual o asociarse a repercusión hemodinámica valvular como se muestra en nuestro caso ${ }^{5}$. Asimismo, se ha sugerido que esta afectación está asociada a una mayor predisposición de desarrollar endocarditis infecciosa debido al daño provocado por el flujo turbulento que discurre a través de la válvula anormal ${ }^{6-7}$.

\section{CONSIDERACIONES FINALES}

La válvula mitral en paracaídas-like es una anomalía congénita caracterizada por una disposición asimétrica de los músculos papilares. Su evolución es muy variable, pudiendo pasar desapercibida o afectando de forma significativa a la mecánica valvular. El estudio de los músculos papilares debe realizarse de forma rutinaria en imagen cardiaca para así detectar alteraciones que interfieran en la correcta dinámica valvular.

Limitaciones de responsabilidad

La responsabilidad del trabajo es sólo de los autores

\section{Conflictos de interés}

Ninguno de los autores declara conflicto de interés ni ha recibidocompensación monetaria ante la realización o publicación de este artículo.

Fuentes de apoyo

No hubo fuentes de financiación ni apoyo.

Originalidad del trabajo

Este artículo es original y no ha sido enviado para su publicación a otro medio de difusión científica en forma completa ni parcialmente.

\section{Cesión de derechos}

Los participantes de este trabajo ceden el derecho de autor a la Universidad Nacional de Córdoba para publicar en la Revista de la Facultad de Ciencias Médicas y realizar las traducciones necesarias al idioma inglés.

Participación de los autores

Todos los autores hemos participado en la concepción del diseño, recolección dela información y elaboración del manuscrito, haciéndose públicamente responsables de su contenido y aprobando su versión final.

\section{Bibliografía}

1. McCarthy KP, Ring L, Rana BS. Anatomy of the mitral valve: understanding the mitral valve complex in mitral regurgitation. Eur J Echocardiogr. 2010 Dec;11(10):i3-9. doi: 10.1093/ejechocard/jeq153.

2. Axel L. Papillary muscles do not attach directly to the solid heart wall. Circulation. 2004 Jun 29:109(25):3145-8. doi: 10.1161/01.CIR.0000134276.06719.F3.

3. Rajiah P, Fulton NL, Bolen M. Magnetic resonance imaging of the papillary muscles of the left ventricle: normal anatomy, variants, and abnormalities. Insights Imaging. 2019 Aug 19;10(1):83. doi: 10.1186/s13244-019-0761-3.

4. Mochizuki Y, Tanaka H, Fukuda Y, Hirata K. An uncommon case of isolated parachute-like asymmetric mitral valve in an adult. J Heart Valve Dis. 2014 Sep;23(5):651-3.

5. Rouskas $P$, Giannakoulas $G$, Kallifatidis $A$, Karvounis $H$. Parachute-like mitral valve as a cause of mitral regurgitation. Hippokratia. 2016 Jul-Sep;20(3):238-240.

6. Schaverien MV, Freedom RM, McCrindle BW. Independent factors associated with outcomes of parachute mitral valve in 84 patients. Circulation. 2004 May 18;109(19):2309-13. doi: 10.1161/01.CIR.0000129269.98460.C8.

7. Showkathali R, Birdi I, Khokhar A. Infective endocarditis in a parachute-like asymmetrical mitral valve. Eur J Echocardiogr. 2009 May;10(3):476-8. doi: 10.1093/ejechocard/jep020. 